\title{
Perú 2018: LA PReCARIEdAd Política en tiempos DE LAVA JATO*
}

\author{
Peru 2018: Political Precariousness in the Times of Lava Jato
}

\section{ZOILA PONCE DE LEÓN}

Washington \& Lee University, USA

\section{LUIS GARCÍA AYALA}

Temple University, USA

\begin{abstract}
RESUMEN
Este artículo presenta un análisis de los principales eventos políticos del 2018. Tras la renuncia de Pedro Pablo Kuczynski (PPK) se dio inicio al primer año de mandato de Martín Vizcarra. Su gobierno enfrentó numerosos escándalos alimentados por el caso Lava Jato, resultando en la detención de políticos clave (incluyendo a los expresidentes ppk y Ollanta Humala) y la transformación de los tres poderes del Estado. Además, una serie de audios destaparon una red de tráfico de influencias dentro del Poder Judicial que involucra la protección de políticos y la negociación de puestos y reducción de penas. Como respuesta, el gobierno de Vizcarra impulsó una serie de reformas institucionales vía referéndum, las cuales se enmarcan en un contexto de precariedad institucional.
\end{abstract}

Palabras clave: Perú, Odebrecht, corrupción, democracia, Poder Judicial

\begin{abstract}
This article presents an analysis of the main political events of 2018. After the resignation of Pedro Pablo Kuczynski (РРК), the first year of Martin Vizcarra's government began. His government faced numerous scandals triggered by the Lava Jato case, resulting in the detention of key politicians (including former presidents PPK and Ollanta Humala) and the transformation of the three branches of government. Moreover, a series of audio recordings uncovered a network of illegal under-the-table practices within the Judiciary, which included the protection of politicians and the negotiation of positions and reduction of penalties. In response, Vizcarra's government promoted a group of institutional reforms via referendum, which are set in a context of institutional precariousness.
\end{abstract}

Keywords: Peru, Odebrecht, corruption, democracy, Judiciary 


\section{INTRODUCCIÓN}

El 2018 ha sido, como año político, uno de los más complejos de la última década. Si bien el 2017 terminó con un fallido proceso de vacancia en contra del presidente Pedro Pablo Kuczynski (РPK), resultaba difícil advertir la saturada coyuntura que traería consigo el año siguiente. La administración de PPK llegó a su fin el 21 de marzo de 2018, cuando el entonces presidente renunció a su cargo. Las principales razones tras esta decisión fueron la aparición de audios y vídeos que mostraban una supuesta compra de votos a congresistas de Fuerza Popular, grupo fujimorista y principal bancada parlamentaria en el Congreso, así como pruebas de posibles conexiones entre PPK y la constructora brasilera Odebrecht, en el marco del escándalo Lava Jato. El 23 de marzo, el hasta entonces vicepresidente Martín Vizcarra asumió el cargo de presidente de la República.

Vizcarra empezaba su primer año heredando un "gobierno dividido", con una correlación de fuerzas favorable a la oposición fujimorista y adversa al Ejecutivo (Arce e Incio 2018). A pocos meses de su inauguración, otra serie de audios que mostraban la negociación de puestos y penas dentro del Poder Judicial forzaron al presidente a plantear al Congreso una reforma política y judicial. Así, el presidente propuso diversos cambios a ser aprobados vía referéndum; proceso del cual el gobierno de Vizcarra salió airoso el 9 de diciembre. Mientras tanto, y amparadas en esta ola reformista, continuaban las pesquisas judiciales sobre el financiamiento electoral ilícito y el pago de sobornos a funcionarios por parte de constructoras brasileñas. Estas investigaciones alteraron el establishment político, al punto que Keiko Fujimori, la lideresa de Fuerza Popular, se encuentra actualmente en prisión preventiva, investigada por el delito de lavado de activos.

El artículo analiza el año 2018 tomando como eje central estos hechos, que en forma global muestran las consecuencias políticas de las revelaciones, escándalos e investigaciones judiciales asociadas directa o indirectamente al caso Lava Jato. En Perú, como en pocos países de la región, el destape de la mega corrupción de Odebrecht y de otras constructoras tuvo un efecto demoledor sobre las principales figuras políticas del país, las cuales, casi sin excepción, se encuentran investigadas por la Fiscalía. Estos avances, así como las propuestas de reforma, parecen reflejar cierta recuperación de la confianza en los poderes Ejecutivo y Judicial y el fortalecimiento del Estado de Derecho. Sin embargo, la baja aprobación del Congreso, la precariedad de las organizaciones partidarias y la débil percepción de representación democrática de la población, nos mantienen aún alertas con respecto al futuro democrático del país.

La siguiente sección presenta un resumen de la coyuntura social y económica peruana durante el 2018, así como un breve recuento de la coyuntura internacional. Luego, proporcionamos un análisis de la coyuntura política durante este año, dividido por cada poder del Estado. Finalmente, resumimos los principales resultados de las elecciones subnacionales y concluimos con algunos comentarios respecto a la calidad de la democracia en el Perú. 


\section{COYUNTURA SOCIOECONÓMICA E INTERNACIONAL}

\section{Coyuntura social}

Durante el 2018, los aspectos más resaltantes de la coyuntura social se focalizaron principalmente en las áreas urbanas: la creciente preocupación ciudadana por el incremento del crimen organizado, las reacciones públicas ante la violencia de género y la corrupción política y la percepción sobre la migración venezolana. No obviamos, sin embargo, tensiones sociales como la violencia narcoterrorista en el VRAEM (valle de los ríos Apurímac, Ene y Mantaro) y ciertos conflictos sociales.

La inseguridad ciudadana es todavía el problema más importante del país (Carrión et al. 2018). Mientras la última encuesta de LAPOP no muestra una diferencia en la percepción comparada con el 2014, los indicadores de homicidios sí evidencian un inquietante ascenso: la tasa de homicidios pasó de 5.4 a 7.8 (por cada 100 mil personas) entre 2011 y 2018 (CEIC 2018). Si bien estas cifras no se alejan del promedio latinoamericano, el panorama cambia en el nivel subnacional. Así, mientras en Lima Capital, la tasa de homicidios calificado por habitante es de 4.1, en la región de Madre de Dios, fronteriza con Brasil — donde florecen economías como la tala y la minería ilegal- este indicador alcanza un pico de 23 (CEIC 2018: 50).

El crimen organizado vinculado al narcotráfico y la extorción es noticia en las ciudades de la costa centro y norte. Perú es uno de los mayores productores de cocaína en el mundo; en el 2017 la producción alcanzó su máximo nivel en tres décadas, con un potencial de 491 toneladas (Office of National Drug Control Policy 2018). El puerto de Callao ha sido un punto estratégico, donde políticos locales y criminales obtenían protección de la judicatura local (Soberón 2018). El lavado de activos también es un problema en ciudades como Tumbes, Chiclayo y Trujillo. En esta última ciudad, la extorsión ha seguido desplegándose sobre pequeños empresarios, comerciantes y pequeños transportistas. Adicionalmente, redes criminales han logrado capturar ciertas municipalidades. Durante el 2018 fueron denunciadas y apresadas una serie de autoridades locales por vínculos con mafias de extorsionadores y traficantes de terrenos, o por ser cabecillas de estas organizaciones. Así, Elías Cuba, exalcalde del distrito de La Victoria, fue acusado de liderar una red que cobraba cupos a ambulantes informales y microempresarios, que recaudaba 25 millones de soles al año (Briceño 2018).

La corrupción ocupaba el segundo lugar como problema más importante, con un 27\% (Carrión et al. 2018). El 91\% de personas creía que la mitad o más de la mitad de los políticos están involucrados en actos de corrupción (Carrión et al. 2018). Incluso, una encuesta de abril de 2018 de IPsos mostró que este problema había desplazado a la delincuencia del primer lugar (La Rosa 2018). Ante los escándalos de corrupción se realizaron una serie de manifestaciones, 
principalmente en Lima, convocadas por colectivos civiles; las marchas, aunque poco numerosas, recibieron cobertura mediática (Perú 21 2018b) ${ }^{1}$.

Durante el 2018 se registró la mayor cantidad de muertes por feminicidio desde que se tiene registro, con 149 casos (MIMP 2019). En los últimos meses, este fenómeno tuvo amplia cobertura en los medios masivos (Fuentes 2019). Eyvi Agreda, Juanita Mendoza, Estéfani Gamboa: algunos nombres que resonaron en la opinión pública. El Estado, sin embargo, no ha respondido adecuadamente ante el problema. La Ley 30.364, creada para "prevenir, sancionar y erradicar la violencia contra las mujeres y los integrantes del grupo familiar" posee elementos rescatables, pero también deficiencias, principalmente en el seguimiento a su correcta implementación (Santos 2018). Este clima de impunidad ha alentado, en el marco del movimiento internacional \#NiUnaMenos, protestas organizadas por colectivos en contra de la violencia de género.

El flujo de migración venezolana a Perú no aminoró en el 2018. Según datos de la Superintendencia Nacional de Migraciones, entre inicios de 2017 y octubre de 2018 migraron a Perú alrededor de 530 mil personas. A partir de octubre de 2018, sin embargo, se aplicaron mayores restricciones para la obtención de carné de residencia (requisito para trabajar y estudiar legalmente en el país). De acuerdo con datos del Organismo de las Naciones Unidas para la Migración, Perú es un país de destino migratorio pero de estancia temporal (oIm y Unicef 2018). La migración venezolana ha generado anticuerpos; una encuesta de setiembre mostraba que el 55\% de limeños no estaba de acuerdo con la llegada de migrantes. Este rechazo ha sido aprovechado por candidatos locales que emplean discursos abiertamente xenófobos (como lo hecho por el candidato Ricardo Belmont durante parte de la campaña para la alcaldía de Lima).

Destacamos dos últimas problemáticas. En el 2018 la violencia del narcotráfico en el VRAEM generó el desplazamiento de familias a consecuencia del amedrentamiento y los asesinatos selectivos a manos de los remanentes de Sendero Luminoso (Vera y Meza 2018). En cuanto a los conflictos sociales, se registraron un total de 232, el menor número en los últimos diez años ${ }^{2}$. No obstante, resaltan tensiones latentes en el asentamiento minero de Las Bambas, en Apurímac y en el (re)intento de explotación en Tía María, Arequipa. En ambos lugares, las expectativas del empresariado por repotenciar el sector minero son altas. El gobierno de Vizcarra optó, hasta el momento, por una estrategia elusiva. Esa misma reacción se apreció en otros conflictos. En mayo, frentes de defensa del sur del país convocaron a paralizaciones a raíz de la implementación del Impuesto Selectivo al Consumo, la cual fue, finalmente revocada ${ }^{3}$.

Incluso un medio de prensa popular como Trome (del grupo El Comercio, uno de los diarios más vendidos en habla hispana) le dedicó una portada favorable a quienes marcharon exigiendo "castigo para jueces y fiscales mafiosos". Ver Trome 2018.

Según datos del Sistema de Monitoreo de Conflictos Sociales (sImco) de la Defensoría del Pueblo (2018).

La reversión de esta medida provocó la renuncia del entonces ministro de Economía y Finanzas David Tuesta. 


\section{Coyuntura económica}

A diferencia de años recientes, durante los cuales el país experimentó un proceso de desaceleración económica (Muñoz y Guibert 2016; Arce e Incio 2018), el 2018 trajo un aumento del crecimiento del PBI (4\%). Como muestra el gráfico 1, a partir del 2011 se observa un descenso del crecimiento económico, explicado en parte por la baja en el crecimiento del sector de minería metálica (BCRP 2019). El repunte experimentado en el 2018 se explica gracias a la mejora en los sectores agropecuario y pesca.

Gráfico 1: Variación anual del PBI real (\%) 2000-2018

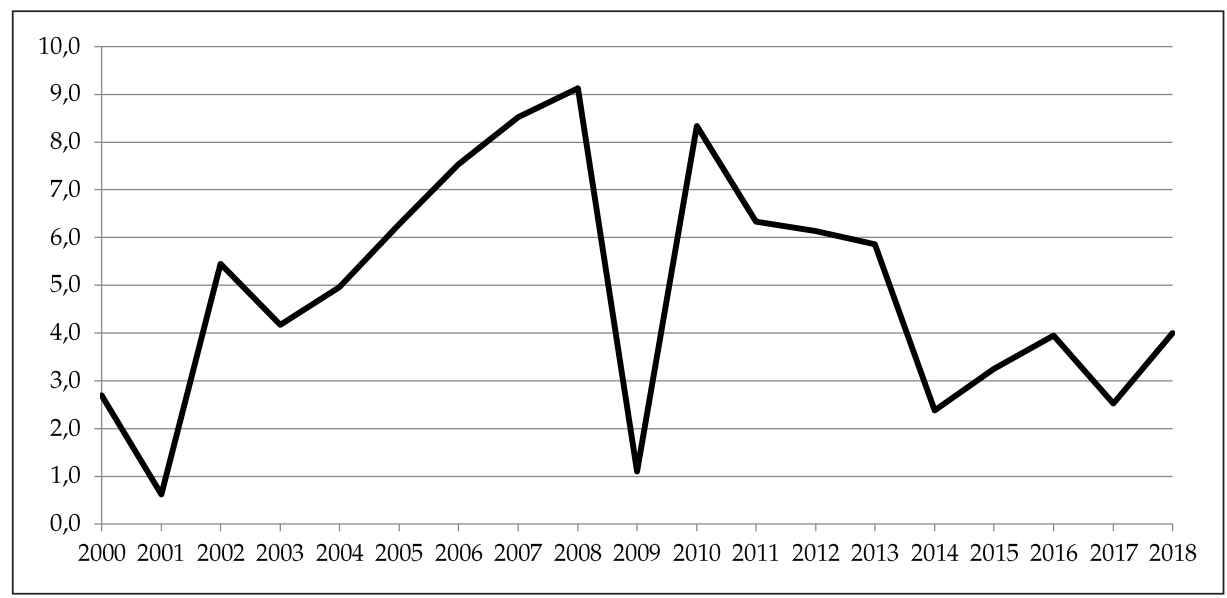

Fuente: elaboración propia en base a datos de всRP \& World Bank Data

La ligera mejora en términos del crecimiento del PBI también se refleja en la reducción de la incidencia de la pobreza en el 2018 (gráfico 2). En este año, 20,5 $\%$ de la población (más de 6,5 millones de peruanos) se encontraron en situación de pobreza, lo que representa una disminución de 1,2 puntos porcentuales en comparación con la cifra del 2017. El incremento de la pobreza apreciado en el 2017 afectó principalmente al área rural (44,4\%, versus 15,1\% en el área urbana). Sin embargo, en el 2018 la pobreza en el área rural disminuyó a 42,1% y a 14,4 \% en el área urbana. La pobreza extrema también disminuyó durante el 2018. En cuanto a la inflación, el año 2018 (2 \%) registró un ligero incremento respecto al 2017 (1,36\%). 
Gráfico 2: Incidencia de la pobreza total y extrema (2004-2018)

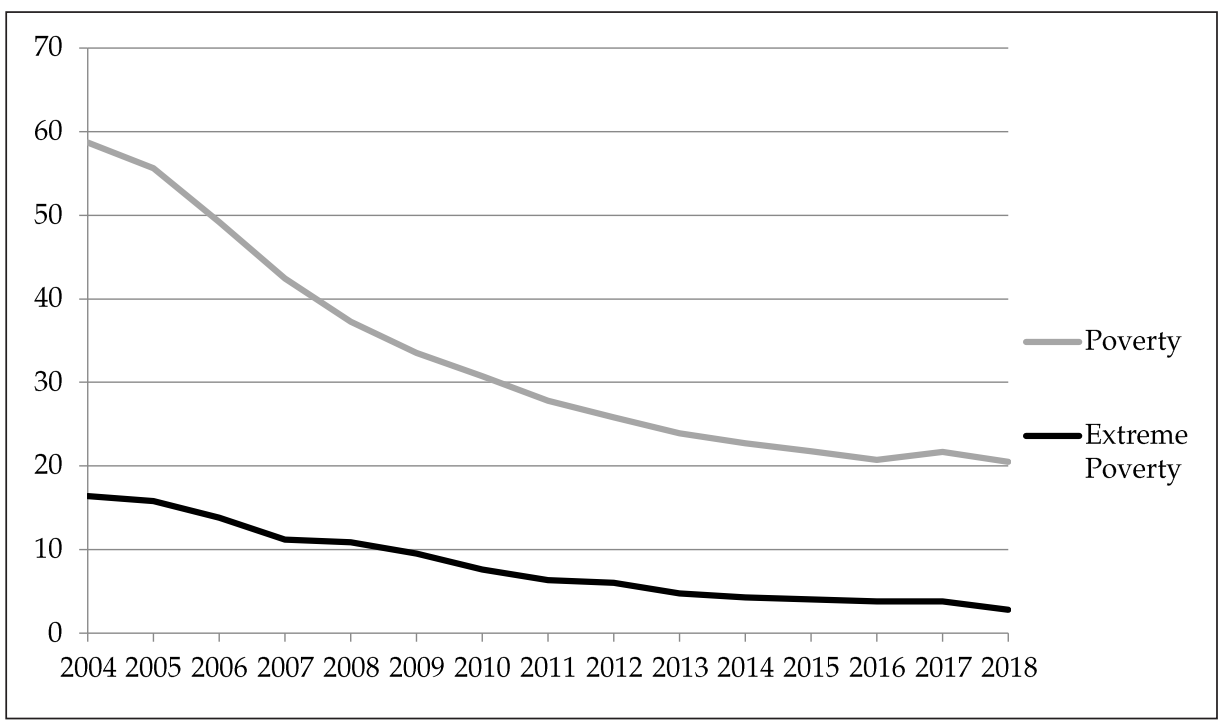

Fuente: elaboración propia en base a datos del INEI

Durante el 2018, tanto la tasa de empleo formal (27,6 \%) como la de empleo informal $(72,4 \%)$ se mantuvieron relativamente estables en comparación con las del 2017 (27,5\% y 72,5\%, respectivamente) (INEI 2019). Mientras que el empleo informal constituye el 65,7 \% del empleo en el área urbana, asciende a 95,6\% en el área rural. En la zona urbana, el empleo formal creció en las ramas de agricultura, pesca y minería $(10,4 \%)$, construcción (14,9 \%) y servicios (2\%).

\section{Coyuntura internacional}

El escenario regional del Perú, así como el de muchos países latinoamericanos, estuvo definido por el escándalo Lava Jato, el cual envuelve a la constructora brasilera Odebrecht en el pago de sobornos a funcionarios públicos y políticos. Distintos países de la región se han visto involucrados en este escándalo, incluyendo Perú, Argentina, México, Colombia, Venezuela y Panamá. En el Perú, como detallamos en la siguiente sección, ha envuelto a prácticamente todos los actores políticos relevantes de las últimas dos décadas, incluyendo a los expresidentes PPK, Ollanta Humala, Alan García y Alejandro Toledo; así como a Keiko Fujimori, lideresa del partido Fuerza Popular.

Durante el 2018, el Perú mantuvo un rol importante como miembro del Grupo de Lima. Este organismo multilateral, formado en agosto del 2017 con el fin de buscar salidas a la crisis venezolana, es conformado por representantes de doce países (Argentina, Brasil, Canadá, Chile, Colombia, Costa Rica, Guatemala, Honduras, México, Panamá, Paraguay y Perú). El grupo condenó las elecciones 
presidenciales del 20 de mayo en Venezuela "por no cumplir con los estándares internacionales de un proceso democrático, libre, justo y transparente" (Comunicado Conjunto 009-18). Además de elecciones libres, el grupo exige la liberación de los presos políticos y la investigación de posibles crímenes de lesa humanidad cometidos en el país sudamericano.

\section{COYUNTURA POLÍTICA}

La coyuntura peruana durante el 2018 (y hasta los primeros meses del 2019), una de las más complejas de la década, alteró el acontecer de los tres poderes del Estado. Esta apiñada agenda política — los peruanos presenciamos dos intentos de vacancia presidencial, una renuncia final, la instalación de un nuevo gobierno, escándalos en la Judicatura y reformas constitucionales- estuvo marcada por el escándalo de Odebrecht y sus efectos demoledores sobre el establishment político local. Casi ningún actor relevante de la escena política postautoritaria quedó fuera de ser asociado al financiamiento ilícito y al pago de sobornos por parte de constructoras brasileñas.

En el Perú, como en pocos países de la región, las investigaciones fiscales progresaron, dictaminándose en su mayoría la detención preliminar, incluso contra expresidentes. Jorge Barata, exrepresentante de Odebrecht en Perú, había prometido a Alejandro Toledo la entrega de 36 millones de dólares a cambio de ganar la licitación de la carretera Interoceánica Sur; Toledo es hoy prófugo de la justicia. Alan García era investigado por los aportes de Odebrecht a la campaña electoral de 2006; el 17 de abril de 2019, el mismo día que se dictaminó su detención preliminar, se suicidó de un tiro en la cabeza. Ollanta Humala, tras nueve meses de prisión preventiva, por la entrega de tres millones de dólares para la campaña del 2011. Jorge Barata también declaró que Odebrecht otorgó trescientos mil dólares a la campaña de PPK de 2011. Por problemas de salud, la situación legal del expresidente cambió de prisión preventiva — dictada en abril de 2019- a la de arresto domiciliario. De otra parte, desde octubre de 2018, la excandidata de Fuerza Popular se encuentra en prisión mientras continúan las investigaciones fiscales por lavar cerca de un millón de dólares para su campaña de 2011 (El Comercio 2019a; Fowks 2019).

La dinámica en los tres poderes también cambió a la par de nuevos escándalos políticos gatillados o alimentados por el caso Odebrecht. En julio de 2018, el Grupo Constelación de la Dirección Antidrogas de la Policía Nacional filtró audios a la prensa, en los que se escucha a distintos jueces de la Corte Suprema de Justicia y del Consejo Nacional de la Magistratura (CNM) negociar puestos, así como reducir penas. El escándalo de los CNM Audios reveló el funcionamiento de una red de favores de protección a políticos implicados en diversos delitos. La capacidad de influencia sobre el Consejo Nacional de la Magistratura es clave en tanto tiene la potestad de alterar la designación de jueces y fiscales. Pero también reveló la importancia para las agrupaciones políticas de mantener 
activa una red de contactos en la Corte Suprema (última instancia judicial) y en el Ministerio Público (entidad encargada de llevar a cabo la investigación). Se supo así que la bancada de Fuerza Popular presionaba para evitar el avance de las investigaciones del caso Odebrecht. El resultado del trabajo de ciertos jueces y fiscales generó indignación en la opinión pública y reformas institucionales canalizadas por el gobierno de Vizcarra.

\section{Poder Ejecutivo}

En diciembre de 2017, PPK había sobrevivido al pedido de vacancia gracias a la abstención de diez miembros de Fuerza Popular ${ }^{4}$. Sin embargo, la razón tras esta victoria significaría el fin de su administración. Tres días después de la votación del pedido de vacancia, PPK otorgó el indulto humanitario al expresidente Alberto Fujimori, quien cumplía una condena de veinticinco años por delitos de lesa humanidad. Distintas fuerzas políticas se manifestaron en contra de esta decisión, principalmente por su conexión con la abstención de los congresistas fujimoristas en la votación para la vacancia.

Durante 2018, la presidencia de PPK se vio sumergida en su segundo proceso de vacancia y los escándalos alrededor de este proceso ${ }^{5}$. En enero, el entonces presidente y la presidenta del Consejo de Ministros Mercedes Aráoz decidieron recomponer el gabinete como respuesta ante la mellada reputación del Ejecutivo. El denominado "gabinete de la reconciliación" mantuvo once ministros y nombró ocho nuevos (Fowks 2018). Este tercer gabinete ni cumplió su meta de apaciguamiento político ni tuvo suficiente tiempo para generar cambios sustanciales de política pública.

PPK se vio cercado por la movilización de un sector de la población, las sesiones de la Corte Interamericana de Derechos Humanos (Corte IDH) y, finalmente, el inicio de un segundo proceso de vacancia en su contra. Durante los últimos días de 2017 y los primeros del siguiente, se realizaron múltiples marchas en Lima y en distintas partes del país en contra del indulto a Fujimori, lideradas por organizaciones de estudiantes y colectivos sociales en defensa de los derechos humanos. Además, distintas encuestas mostraban que la mayoría de los peruanos percibía el indulto como producto de una turbia negociación entre el líder de la rebelde minoría fujimorista, Kenji Fujimori, y PPK (Fowks 2018a). En febrero, la Corte IDH llevó a cabo una audiencia pública con el fin de determinar si el Estado peruano estaba cumpliendo con su obligación de

$4 \quad$ El Frente Amplio pidió la vacancia del presidente por incapacidad moral, algo que la bancada fujimorista respaldó. El pedido fue hecho en base a la información que la comisión investigadora multipartidaria del Congreso presentó, la cual mostrara pagos hechos por Odebrecht por un total de us $\$ 4,8$ millones a dos compañías de asesoría vinculadas a РPK. Varios de estos pagos fueron hechos durante la administración de Alejandro Toledo (2001-2006), cuando PPK era ministro de Economía y Finanzas. Ver BBC 2018.

5 Tras el indulto al expresidente Fujimori el 24 de diciembre, dos ministros renunciaron a sus cargos (Cultura y Defensa). 
sancionar a Alberto Fujimori por los delitos cometidos en los casos Barrios Altos y La Cantuta (Corte IDH 2018).

En marzo, el Congreso aprobó un segundo proceso de vacancia contra PPK, nuevamente por incapacidad moral y por su presunto vínculo con Odebrecht. Sin embargo, la votación de este nuevo pedido nunca se llevó a cabo. Días antes de la votación, el congresista de Fuerza Popular Moisés Mamani entregó al Ministerio Público vídeos y audios que muestran sus conversaciones con ministros e integrantes del bloque congresal liderado por Kenji Fujimori durante el primer proceso de vacancia: en ellos se observa el ofrecimiento de obras públicas a cambio de votos. A este escándalo se sumó la filtración de un documento de la Unidad de Inteligencia Financiera de Perú que mostraba la transferencia de tres millones de dólares a cuentas personales de PPK de las dos firmas de asesoría que habían recibido dinero de Odebrecht (ввс 2018).

Kuczynski negó tajantemente haber participado de la presunta compra de votos de los congresistas miembros de Fuerza Popular, así como haber recibido dinero de Odebrecht mientras cumplía un cargo público. Pese a ello, dimitió a su cargo el 21 de marzo. Tras enviar su carta de renuncia al Congreso, los parlamentarios debatieron su aceptación, para aprobarla con ciento cinco votos a favor, doce en contra (miembros de Peruanos por el Kambio) y cuatro abstenciones (El Comercio 2018a) ${ }^{6}$. El entonces primer vicepresidente Martín Vizcarra asumió el mando el 23 de marzo, dejando su cargo como embajador en Canadá.

Vizcarra puso énfasis en la lucha anticorrupción desde el inicio de su gobierno, con la intención de dejar en claro que su administración marcaba una distancia clara con la anterior. En esa misma línea, prometió una reestructuración completa del gabinete en un plazo de diez días. Esta actitud contrastaba con la de otros miembros de la coalición partidaria que lo llevó a la vicepresidencia, Peruanos por el Kambio, cuyos miembros manifestaban que el nuevo gobierno de Vizcarra continuaría con la línea del gobierno anterior (Perú21 2018).

Pocos días antes de que el presidente anunciara su nuevo gabinete, el Ejecutivo nombró un nuevo ministro de Transportes y Comunicaciones, en reemplazo de Bruno Giuffra, quien se encontró implicado en el escándalo de compra de votos de congresistas durante el primer proceso de vacancia de PPK. Vizcarra nombró presidente del Consejo de Ministros a César Villanueva (Alianza para el Progreso). Esta designación fue criticada por algunos sectores, incluyendo miembros de Peruanos por el Kambio, debido a que Villanueva fue el congresista que promovió el segundo proceso de vacancia. El gabinete del presidente Vizcarra no ha gozado de mucha estabilidad hasta el momento, con un total de dieciocho cambios durante su primer $\mathrm{añ}^{7}$. Aunque, en comparación con el año y ocho meses de Pрк (44), la estabilidad del gabinete de Vizcarra parezca mayor,

6 Parlamentarios de las distintas bancadas aceptaron la renuncia de PРК pero no los términos de su carta, debido a que en esta el mandatario se desvincula de las acusaciones hechas en su contra. Ver El Comercio 2018b. Este dato incluye cambios hasta el 11 de marzo de 2019, cuando Salvador del Solar fue nombrado nuevo presidente del Consejo de Ministros y nueve ministros fueron reemplazados. 
si observamos los cinco años de gobierno de Alan García (24) y de Alejandro Toledo (27) (Arce e Incio 2018), el Ejecutivo luce inestable.

Otro punto importante del mensaje de Vizcarra como nuevo presidente fue la búsqueda de estabilidad institucional. Sin embargo, el presidente se vio forzado a promover significativas reformas institucionales. Como respuesta ante el escándalo de los CNM Audios, Vizcarra anunció que su gobierno impulsaría una reforma urgente del sistema judicial, empezando con la creación de la Comisión de Reforma del Sistema de Justicia. A pocos días de este anuncio se difundió un audio que evidenciaba la negociación de cargos entre el ministro de Justicia Salvador Heresi y el juez supremo César Hinostroza. Vizcarra pidió la renuncia inmediata del ministro.

Vizcarra anunció que su gobierno convocaría a un referéndum para aprobar las reformas constitucionales, tanto del sistema judicial como del Congreso, con el fin de hacerle frente a la corrupción que parecía haberse apoderado de estos poderes del Estado. Antes de poder ser sometidas a referéndum, el Congreso debía aprobar cuatro medidas: la reforma del CNM, la regulación del financiamiento privado a los partidos políticos, la no reelección inmediata de congresistas y el retorno a la bicameralidad. Fuerza Popular — aún el principal partido de oposición en el Congreso - fue muy crítico de estas reformas que catalogó de populistas; en particular, la no reelección de congresistas.

El Ejecutivo consideró que el Congreso estaba obstruyendo su reforma constitucional a través de la demora en el debate de las cuatro medidas. La estrategia de respuesta del Ejecutivo fue frontal: en septiembre, Vizcarra decidió enviar al presidente del Consejo de Ministros a plantear la "cuestión de confianza" ante el Congreso. A través de este mecanismo, el Congreso decide otorgar, o no, su confianza al gabinete. En agosto de 2017, el Congreso le negó su confianza al gabinete (Arce e Incio 2018); si los parlamentarios negaban la confianza a un segundo gabinete, corrían el riesgo de perder sus puestos ${ }^{8}$. Además, César Villanueva dejó en claro que la confianza debía incluir el compromiso de aprobar las cuatro reformas antes del 4 de octubre de 2018 para garantizar que el referéndum tomara lugar a principios de diciembre) (El Comercio 2018c). El Congreso le otorgó su confianza al gabinete y aprobó las cuatro reformas antes de la fecha establecida.

El 9 de diciembre, los peruanos debían votar las cuatro reformas enmendadas y aprobadas por el Congreso. De aprobarse la primera reforma, el CNM sería disuelto en 2019 y la nueva Junta Nacional de Justicia (JNJ) estaría a cargo de nombrar y destituir jueces y fiscales. La segunda reforma buscaba fortalecer la regulación del financiamiento de los partidos políticos, incluyendo la sanción penal del financiamiento ilícito y prohibiendo la contratación de publicidad en 
los medios de comunicación. De aprobarse, la difusión de propaganda electoral solo podría tomar lugar durante la franja de tiempo que otorga el Estado a los distintos partidos. La tercera planteaba la prohibición de la reelección inmediata de congresistas. Finalmente, la última propuesta buscaba el retorno a la bicameralidad en el Congreso 9 .

El presidente Vizcarra pidió a los electores votar en contra de la bicameralidad, aduciendo que el Congreso había desnaturalizado su propuesta original. La propuesta que el Congreso aprobó en octubre eliminaba la capacidad del presidente de disolver el Congreso si este negara su confianza a dos gabinetes. Además, omitía una cláusula que el Ejecutivo incluyó originalmente sobre la paridad de género en las listas de candidatos al Congreso (ввс 2018b). Las propuestas, con excepción de la bicameralidad, fueron aprobadas por la mayoría de los peruanos. El Ejecutivo salió airoso de esta "cruzada en contra de la corrupción", como la enmarcó el gobierno en busca de ganar el apoyo de la población: más del 85 \% de los votos respaldaron las tres primeras propuestas y más de 90 \% rechazaron la última.

El Ejecutivo aprovechó la coyuntura favorable de los resultados del referéndum para anunciar la creación de la Comisión de Alto Nivel de Reforma, la cual se encargaría de proponer distintos cambios políticos, incluyendola reglamentación al financiamiento de los partidos políticos, así como la revisión de la inmunidad parlamentaria y del sistema de voto preferencial ${ }^{10}$. Una vez listas, las incitativas serían revisadas por el Ejecutivo y enviadas al Congreso.

El presidente Vizcarra decidió usar el impulso de una reforma constitucional como estrategia para romper con el alto nivel de conflicto Ejecutivo-Legislativo que caracterizó al gobierno de PPK. Planteó límites de tiempo claros al Congreso y cuando este no respondió, decidió usar el mecanismo de "cuestión de confianza" para presionar a los parlamentarios. De esta manera, Vizcarra logró lo que su antecesor no: escapar a la obstrucción que Fuerza Popular y su lideresa Keiko Fujimori representaban para el gobierno. Si bien es cierto que las dificultades intrapartidarias que Fuerza Popular tuvo ayudaron a este proceso, no podemos ignorar el manejo político de Vizcarra y su equipo.

Su estrategia no solo redujo la tensión entre estos dos poderes, también dio una respuesta clara a la población que sentía que la corrupción crecía y amenazaba las distintas ramas del Estado (GCв 2017). La aprobación presidencial tuvo un crecimiento abismal entre julio y noviembre (gráfico 3). Incluso, la aprobación de la gestión del Ejecutivo creció entre julio y octubre (gráfico 4). Vizcarra ha conseguido generar una conexión con el electorado peruano — por lo general, apolítico- gracias a su apoyo constante a las marchas anticorrupción, así

$9 \quad$ Hasta 1992, el Perú contaba con dos cámaras: una de senadores y otra de diputados. Tras el autogolpe de Alberto Fujimori, quien cerró ambas cámaras, la nueva Constitución de 1993 estableció que el Parlamento sería unicameral.

10 Esta comisión presentó sus propuestas a mediados de marzo de 2019. 
como su rápida respuesta ante el desenvolvimiento de los distintos eventos del escándalo de corrupción del sistema judicial y del proceso de investigación de Keiko Fujimori.

Gráfico 3: Aprobación de Martín Vizcarra y Keiko Fujimori

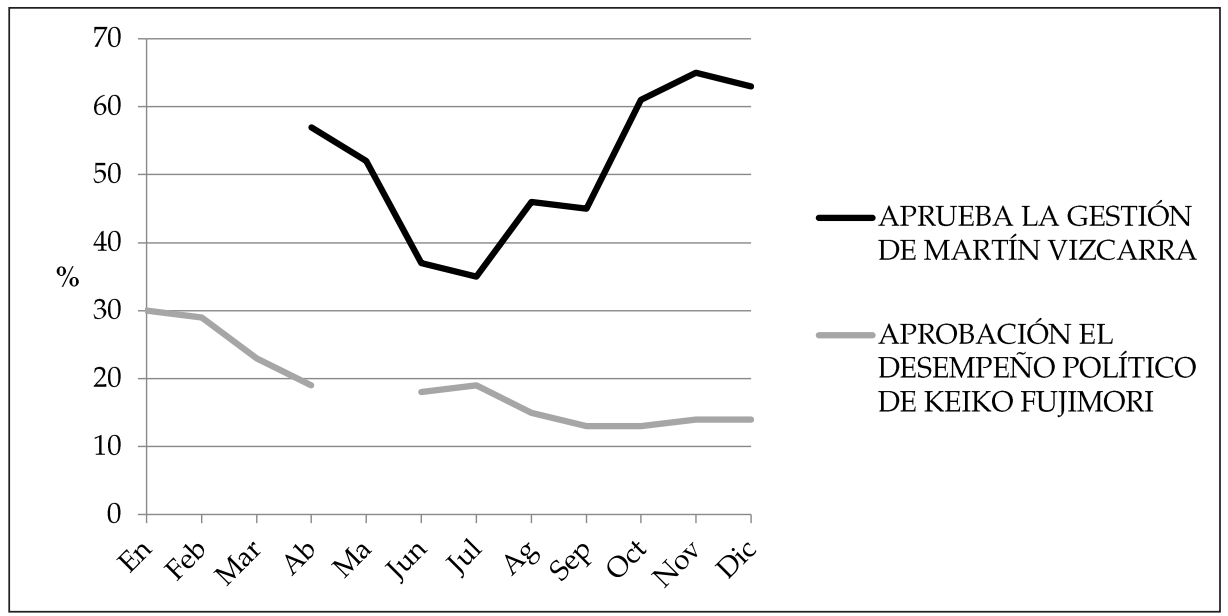

Fuente: elaboración propia en base a datos de El Comercio-IPsos

Gráfico 4: Aprobación de la gestión de los poderes del Estado

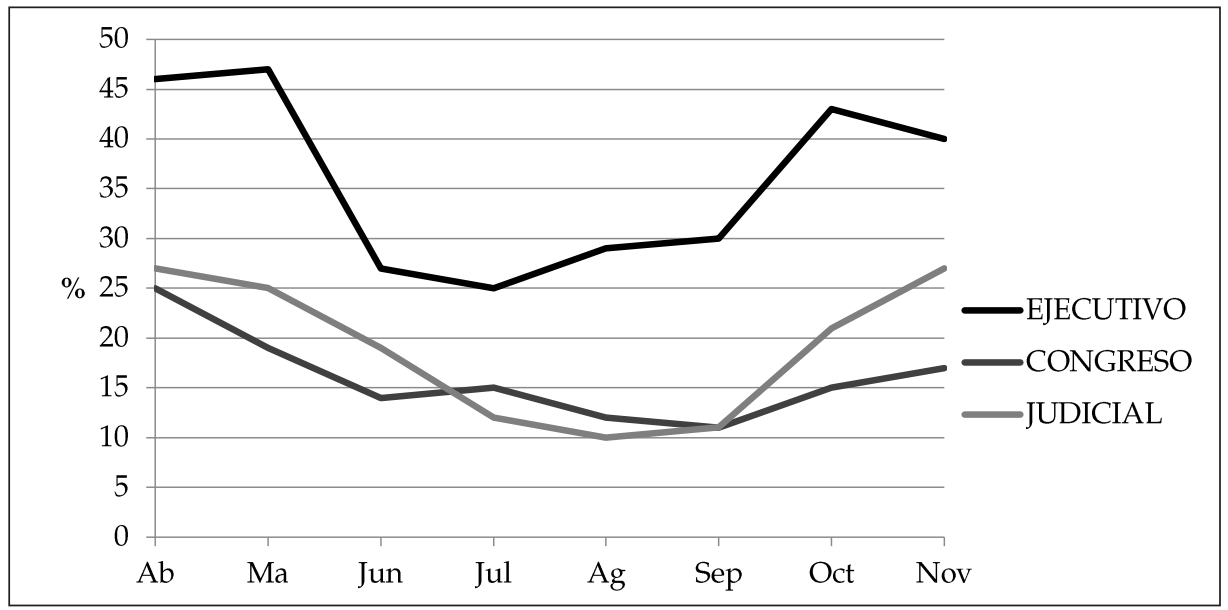

Fuente: elaboración propia en base a datos de El Comercio-IPsos

\section{Poder Legislativo}

Mientras el Ejecutivo se fortalecía con el impulso a las reformas políticas, el Poder Legislativo ingresó en un período de debilidad. Las bancadas desarrollaron una dinámica de atomización: Si bien casi todos los grupos parlamentarios 
han padecido las renuncias de sus congresistas durante el 2018, los partidos más perjudicados fueron Peruanos por el Kambio y, contra ciertos pronósticos, Fuerza Popular. El siguiente gráfico detalla la evolución de la composición de las bancadas hasta enero de 2019.

Gráfico 5: Comparación de bancadas parlamentarias por semestre

\section{Al 28 de julio de 2016}

- Fuerza Popular - 73

Frente Amplio por Justicia, Vida y Libertad - 20 - Peruanos por el Kambio - 18

- Alianza por el Progreso - 9

- Acción Popular - 5

Célula Parlamentaria Aprista - 5

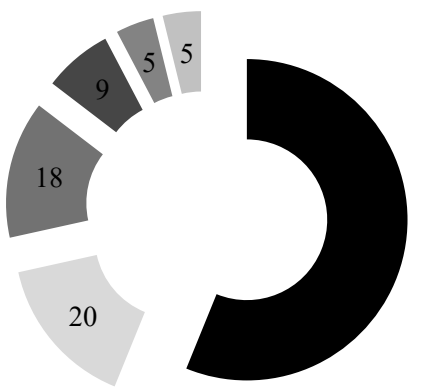

\section{Al 31 de enero de 2018}

- Fuerza Popular - 61

Frente Amplio por Justicia, Vida y Libertad - 10

- Peruanos por el Kambio - 15

- Alianza por el Progreso - 8

- Acción Popular - 5

—Célula Parlamentaria Aprista - 5

- No agrupado - 16

Nuevo Perú - 10

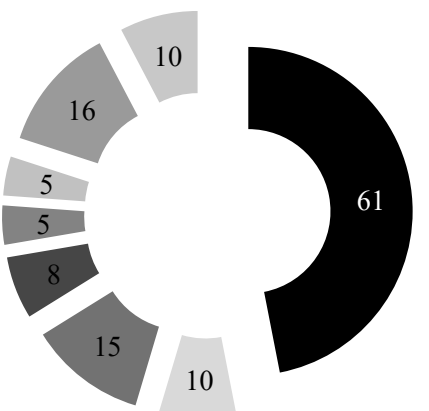

\section{Al 31 de enero de 2019}

- Fuerza Popular - 55

Frente Amplio por Justicia, Vida y Libertad - 9

- Peruanos por el Kambio - 11

- Alianza por el Progreso - 8

- Acción Popular - 5

Célula Parlamentaria Aprista - 5

- No agrupado - 9

Nuevo Perú - 10

- Bancada Liberal - 5

- Unidos por la República* - 5

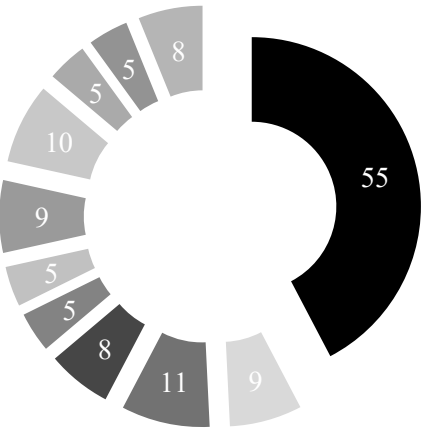

Cambio $21-8$ 
La elección de 2016 había producido una inédita correlación de fuerzas en el Congreso entre los dos partidos que pasaron a segunda vuelta (McNulty 2017; Arce e Incio 2018). Por primera vez desde el retorno a la democracia, la oposición ganaba la mayoría absoluta, con setenta y tres escaños. Hasta antes del primer proceso de vacancia, Fuerza Popular aún controlaba el pleno del Congreso gracias a sus setenta y un votos y a la hegemonía en casi todas las comisiones parlamentarias.

Entre enero de 2018 y enero de 2019, el partido oficialista pierde cuatro representantes. La forma en que Kuczynski evitó ser vacado, mediante el indulto a Alberto Fujimori, generó una primera recomposición en su grupo parlamentario. Renunciaron entonces los congresistas Alberto de Belaúnde, Gino Costa y Vicente Zevallos, del ala liberal del partido. Estas renuncias, sin embargo, no hicieron disminuir las tensiones entre el nuevo gobierno de Vizcarra y algunos miembros de la bancada de Peruanos por el Kambio, pues esta última se sentía ignorada (La República 2018). Para julio, dos años después de las elecciones, solo Acción Popular y el APRA no habían perdido legisladores entre sus filas. A mediados de 2018, el segundo bloque parlamentario más grande era, paradójicamente, el de los "no agrupados", con 16 congresistas ${ }^{11}$.

La atomización durante 2018 se debió a factores de largo y corto plazo. Sobre los primeros, los cambios en las composiciones del parlamento obedecen a patrones que se repiten en todas las últimas legislaturas. Los grupos parlamentarios se componen sobre la base de partidos sin organización, con muchos invitados, alta volatilidad, sin estructura organizacional y sin un mecanismo de reclutamiento claro (Valladares 2010; Campos 2017, 2018). La consecuencia principal ha sido el transfuguismo: en la política peruana pos-Fujimori, los congresistas han tenido menos incentivos para ser disciplinados y permanecer en sus agrupaciones, en tanto los partidos que los acogen no tienen con los primeros ningún vínculo programático ni les ofrecen horizontes temporales de mediano o largo plazo (Campos 2017: 363; Levitsky 2018).

Sobre los segundos, recientes cambios normativos redujeron aún más los costos de desligarse de una bancada parlamentaria. El Tribunal Constitucional dio por fundada la demanda contra la Ley "Antitránsfuga" (que había sido aprobada con los votos del APRA y Fuerza Popular en el 2017). Esta ley prohibía acceder a cualquier cargo ejecutivo dentro del Congreso - ser presidente de una comisión o participar de la Mesa Directiva- a congresistas que abandonen su grupo parlamentario original. El golpe definitivo lo da la prohibición de la reelección inmediata de congresistas, en el marco de las reformas políticas impulsadas por el Ejecutivo. De esta manera, sin muchos incentivos para la permanencia en un bloque parlamentario, los congresistas formaron nuevas bancadas. Para diciembre, la Mesa Directiva había aprobado la inscripción de la Bancada

11 La izquierda, que había ingresado como la segunda fuerza parlamentaria, se había divido en dos bloques (Frente Amplio y Nuevo Perú) un año antes. 
Liberal y de Cambio 21, conformadas por exmiembros del fujimorismo y otras agrupaciones (gráfico 5). Al momento que se escribe este artículo, 11 bloques parlamentarios existen en el Congreso, y uno más se encuentra en proceso de inscripción.

\section{La caída de Fuerza Popular}

Para la sorpresa de muchos, Fuerza Popular también compartió patrones de debilidad. Se había argumentado, aunque en términos relativos, que el fujimorismo era una agrupación tan disciplinada como el APRA y en proceso de institucionalización, percibido como el más organizado del país, con cierto grado de identidad y de inversión de recursos en construcción partidaria (Urrutia 2011; Dargent y Muñoz 2016: 154, Sosa 2016; Levitsky 2018: 51). Tras la renuncia de PPK, en marzo, todo hacía indicar que Fuerza Popular, y su lideresa Keiko Fujimori, mantendrían el control de la agenda política tanto en el parlamento como sobre el Ejecutivo, y que esta hegemonía iba a continuar durante el gobierno de Vizcarra (Tola 2018). Sin embargo, desde la segunda mitad del 2018 Fuerza Popular padeció una serie de reveses: de julio de 2016 a enero de 2019, esta agrupación perdió el 25 \% de sus congresistas. Ello en un contexto en el cual su lideresa, Keiko Fujimori, está detenida con orden de prisión preventiva y el partido mismo ha sido golpeado por una serie de escándalos que lo comprometen con las redes de tráfico de influencias en el CNM.

El primer intento de vacancia provocó una ola de cambios en Fuerza Popular: Kenji Fujimori, junto con otros nueve congresistas, renunciaron al partido, y para marzo de 2018 otros dos congresistas se sumaron a la lista, dejando a la bancada con cincuenta y nueve escaños. Así, se revelaba la división entre la facción "albertista", grupo de congresistas seguidores de Kenji que buscaron a toda costa el indulto de Alberto Fujimori, y la facción "keikista", quienes, con la lideresa del partido a la cabeza, buscaban, al menos en apariencia, tomar distancia de la figura del expresidente.

Después de la renuncia de PPK parecía que Fuerza Popular cedía en su confrontación con el Ejecutivo. Así, el 20 de junio, el Congreso, con los votos mayoritarios de esta bancada, aprobó la delegación de facultades legislativas al Ejecutivo por un plazo de sesenta días (Rosales 2018). No obstante, la bancada fujimorista mantenía el control de la agenda legislativa y logró que, en ese mismo mes, el Pleno aprobara por mayoría la suspensión de Kenji Fujimori y otros dos congresistas, por estar involucrados en la compra de votos para evitar la vacancia de Kuczynski.

La situación, sin embargo, volvió a ser adversa para Fuerza Popular desde julio. El escándalo de los CNM Audios reveló una red de corrupción y de tráfico de influencias en el Poder Judicial, la Fiscalía y en la Corte Nacional de la Magistratura; además de los vínculos que mantenía con esta red el partido 
Fuerza Popular y la necesidad de este último de evitar el avance de las pesquisas judiciales. Por entonces, la hija mayor del expresidente era investigada desde febrero de 2017 por el delito de lavado de activos (Tola 2017). Para el equipo fiscal a cargo del caso, estos vínculos en la judicatura, que se extendían hasta el fiscal de la Nación Pedro Chávarry, querían proteger a Fujimori frente al avance de las investigaciones. En octubre, el juez de la investigación preparatoria penal dictó la prisión preventiva contra Keiko Fujimori, junto con el ex candidato a la vicepresidencia Jaime Yoshiyama, y otras personas involucradas, entre asesores y exministros (Tola 2018).

La prisión preventiva de Keiko Fujimori — primero por diez días y luego por treinta y sesis meses - significó un punto de quiebre para la hegemonía del fujimorismo en la política peruana, al menos de su vertiente "keikista": en un año la bancada fujimorista perdió influencia no solo en el Congreso, también en el ámbito judicial. Aunque es todavía la primera mayoría (al 31 de enero de 2019 contaba con cincuenta y cinco congresistas), ha perdido poder en la Comisión Permanente y en comisiones clave como Ética y Levantamiento de Inmunidad Parlamentaria (La República 2019). Más notorio aún: Fuerza Popular perdió la presidencia del Congreso con la renuncia de Daniel Salaverry a la bancada en enero de 2019. Salaverry había sido elegido presidente en julio de 2018; se desempeñaba, además, como secretario nacional del grupo parlamentario. Desde el escándalo de los CNM Audios, Salaverry tomó una actitud más distante con el partido: primero en los desencuentros con la congresista fujimorista Rosa Bartra, por la desclasificación del informe de la comisión Lava Jato (informe señalado por otras bancadas como "sesgado") (La República 2018b); luego en la aprobación de nuevas bancadas, perjudicando a Fuerza Popular. Salaverry incluso salió airoso de una moción de censura presentada por el fujimorismo en enero de 2019, que no tuvo acogida en otras agrupaciones políticas (Perú21 2019).

\section{Poder Judicial}

Durante 2018, la Judicatura adquirió gran relevancia mediática en el contexto del caso Lava Jato. En julio, el portal IDL-Reporteros difundió, en publicaciones consecutivas, los audios que revelaron el tráfico de influencias en el Poder Judicial, la Fiscalía de la Nación y el CNM. A juicio de ciertos periodistas, estos destapes y la purga de funcionarios abrieron una ventana de oportunidad para el avance de casos como Lava Jato. Los escándalos debilitaron "sustantivamente el mecanismo corrupto de encubrimiento judicial destinado a librar de culpa a los involucrados en este caso" (IDL-Reporteros s.f.).

Igual o más importante fue la firma del acuerdo de cooperación eficaz con Odebrecht, el 8 de diciembre de 2018. En este, el representante de la empresa brasileña se compromete a brindar información ante las autoridades por los hechos delictivos asociados a la ejecución de megaobras de infraestructura en el país. La firma del acuerdo fue consecuencia de la unificación de las 
investigaciones del caso Lava Jato en un único equipo especial en el cual, a su vez, se unifican los criterios de trabajo de los fiscales con relación a la colaboración eficaz (González-Ocampos y Baraybar 2019). La habilidad de los fiscales y jueces para elaborar estos compromisos permitió superar obstáculos técnicos, obtener información de primera mano y conseguir el avance de las investigaciones (González-Ocampos y Baraybar 2019).

Los fiscales Rafael Vela y Domingo Pérez, responsables de las investigaciones a las elites políticas y económicas involucradas en el caso, adquirieron relevancia mediática (González-Ocampos y Baraybar 2019: 84-85). Se generó una ola de activismo judicial (Grompone 2019) con el apoyo de la opinión pública y algunos colectivos civiles, lo que permitía a los funcionarios contrarrestar cierta precariedad institucional. En este activismo - comparable al movimiento italiano "manos limpias" - resulta también clave el papel de un sector de la prensa, pendiente de los primeros avances de las pesquisas para crear un escudo ante la presión de la clase política (Gorriti 2017).

Esto último pues, precisamente, las investigaciones judiciales no estuvieron exentas de intentos por revertir sus avances. El monto de reparación establecido en el convenio con Odebrecht fue objeto de ataques por parte de políticos y periodistas. La propia Fiscalía se convirtió en una arena contenciosa. El fiscal de la Nación Pedro Chávarry decidió, ante el avance de las investigaciones contra Keiko Fujimori, remover a los fiscales Rafael Vela y Domingo Pérez la noche de Año Nuevo. Chávarry había sido cuestionado por sus vínculos con funcionarios involucrados en casos de corrupción (IDL-Reporteros 2018a). La bancada fujimorista, sin embargo, entorpecía la denuncia constitucional contra Chávarry (IDL-Reporteros 2018b). Ante la decisión del fiscal de la Nación, colectivos civiles antifujimoristas se movilizaron otra vez en una serie de protestas de defensa del trabajo fiscal, que propiciaron la reposición de Vela y Pérez en sus cargos (RPP Noticias 2018).

\section{ELECCIONES SUBNACIONALES}

En paralelo al avance de las investigaciones y las detenciones preliminares se inició la campaña para las elecciones regionales y municipales de 2018. En ellas, el desempeño congresal de Fuerza Popular y el APRA tuvo efectos negativos, al punto que no obtuvieron ninguna gobernatura regional. El desprestigio que trajeron los escándalos de Odebrecht y CNM Audios y la obstrucción desde el Congreso a la lucha anticorrupción ahondaron - aún más- en la desaparición de los partidos nacionales en la arena subnacional.

Según información de la Oficina Nacional de Procesos Electorales (ONPE), el 7 de octubre participaron 18800629 asistentes, registrándose un ausentismo del 20 \%. Las elecciones regionales - las quintas desde el 2002- dieron como resultado un panorama bastante similar al de procesos anteriores con predominio de movimientos regionales, alianzas momentáneas entre candidatos municipales 
y regionales y fragmentación del voto (Aragón e Incio 2014; Zavaleta 2014; Aragón y Cruz 2018). Los resultados de las elecciones regionales y municipales del 2018 muestran el retroceso definitivo de los partidos nacionales en la arena regional y municipal (gráfico 6). Una excepción es Alianza para el Progreso, partido de origen regional que nuevamente ha logrado competir en el norte del país, en parte sobre la base de una estrategia clientelista (Barrenechea 2014).

Gráfico 6: Participación de los principales partidos nacionales en elecciones

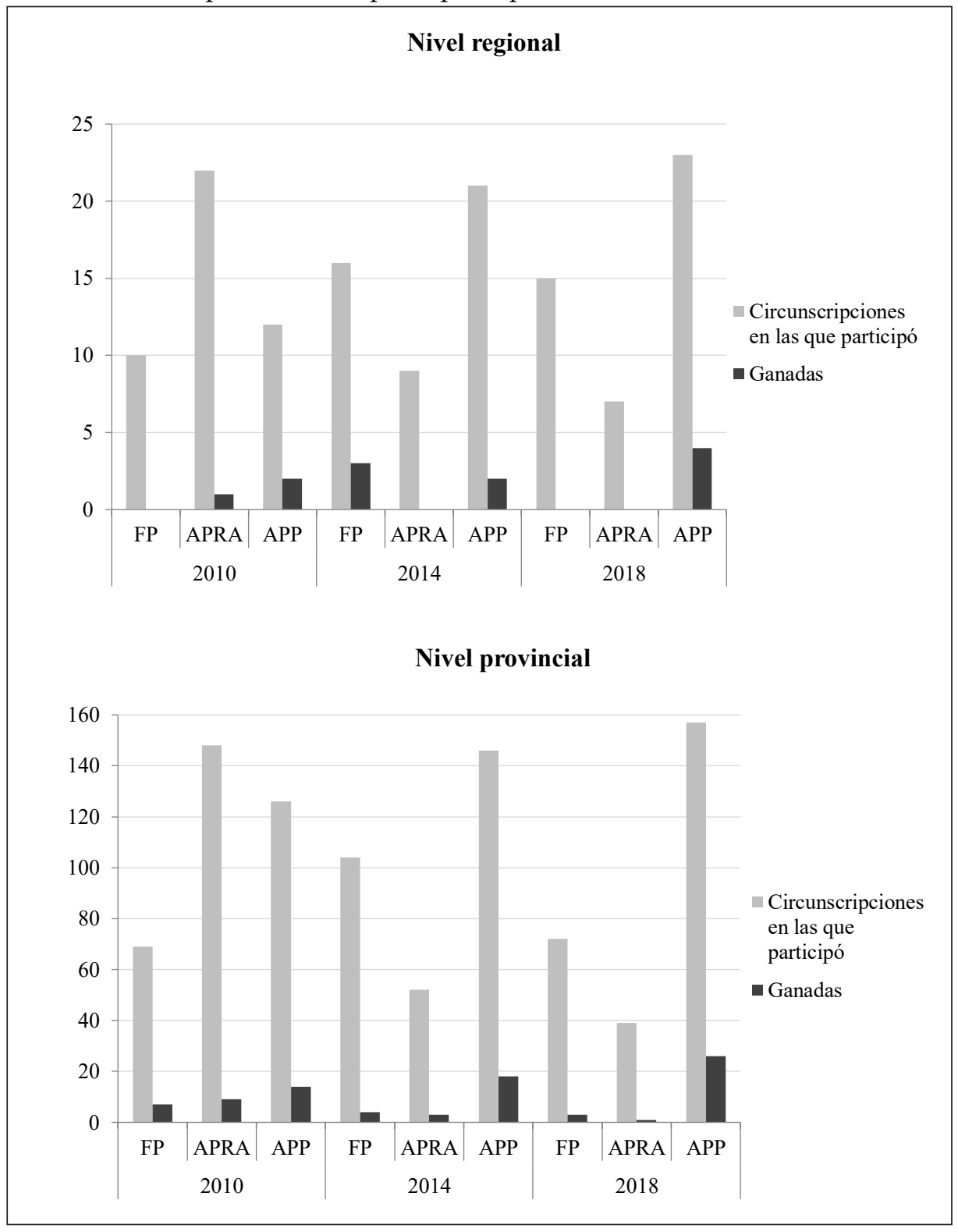


Gráfico 6: Participación de los principales partidos nacionales en elecciones (continuación)

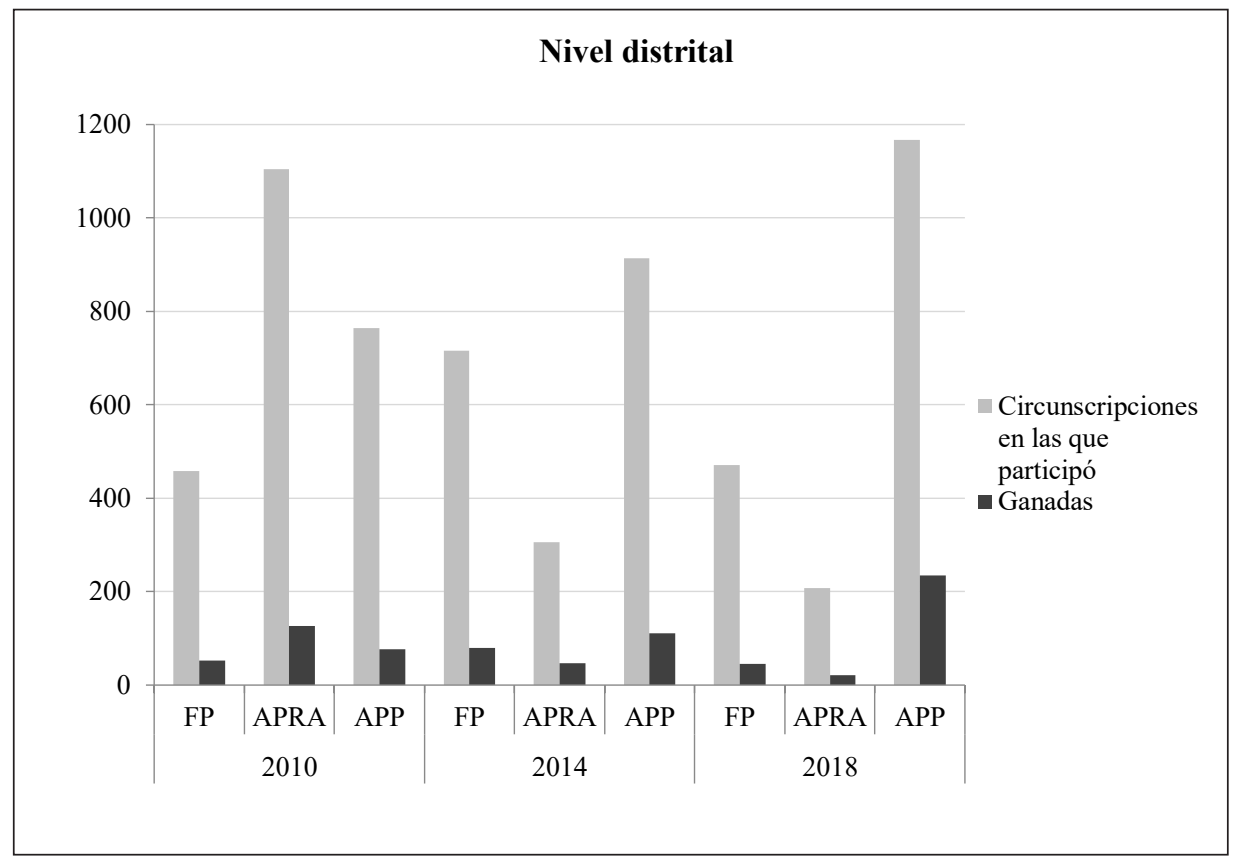

Estas elecciones presentaron, no obstante, un cambio: fueron las primeras elecciones regionales y municipales bajo la prohibición de la elección inmediata, establecida en una ley aprobada por el Congreso en 2015, lo que ha modificado la dinámica de la política subnacional de dos maneras: por parte del elector, quien ahora no tiene la posibilidad de sancionar o premiar el desempeño de su gobernante local; por parte del gobernante, la normativa significó la búsqueda de nuevas estrategias — como postular inmediatamente a cargos más altos (por ejemplo, de alcalde distrital a provincial) o convertir en candidatos a sus parientes más próximos- para continuar con su carrera política (Aragón y Cruz 2018: 35) ${ }^{12}$.

La normativa, sin embargo, es en sí misma contraproducente. En primer lugar, la evidencia muestra que las tasas de reelección son unas de las más bajas de la región y, más bien, ser incumbente puede ser un lastre para el éxito electoral (Córdova e Incio 2013; Aragón e Incio 2014). En segundo lugar, pueden perjudicar el aprendizaje de la gestión pública, considerando la inexperiencia de las autoridades. Finalmente, la prohibición inmediata no parecería atacar la razón por la que fue propuesta: la captura del aparato estatal por parte de 
políticos corruptos y autoritarios depende más de la fortaleza institucional de la rendición de cuentas (Arévalo y Sosa 2016; Muñoz 2016; Vega et al. 2018).

En la capital, en el marco de una opinión pública pendiente de la corrupción, la atención de los medios nacionales no se centró en la campaña sino hasta escasas semanas del día de la elección. Durante los meses anteriores, Renzo Reggiardo, candidato afín al fujimorismo (congresista en el período anterior), y Daniel Urresti, exmilitar y ministro del Interior durante el gobierno de Ollanta Humala, se disputaban el primer puesto. Asimismo, el controvertido exalcalde de Lima, Ricardo Belmont, se perfilaba en el tercer lugar, manejando un discurso con tintes xenófobos frente a la migración venezolana. Sin embargo, fue Jorge Muñoz, el candidato de Acción Popular, quien se llevó el triunfo electoral. Muñoz tuvo un buen desempeño durante los debates televisados y, al parecer, el "boca a boca" y el peso de las redes sociales y los influencers (personas informadas de confianza que conocen o están interesadas en la política) cumplieron un rol predominante en el resultado (Amaya 2018).

\section{CONCLUSIÓN. REFLEXIONES SOBRE LA CALIDAD DE LA DEMOCRACIA}

El 2018 trajo consigo procesos y resultados inesperados para el Perú. Como el análisis que hemos presentado detalla, la coyuntura política peruana del 2018 ha sido una de las más complejas. Dos procesos de vacancia presidencial en menos de tres meses, la renuncia de PPK debido a la presión que acusaciones de compra de votos durante su primer proceso de vacancia y conexiones con Odebrecht ejercieron, escándalos desencadenados por audios que revelan la negociación de puestos y reducción de penas dentro del sistema judicial, y reformas constitucionales que buscaban devolverle a los peruanos un poco de confianza en el sistema político y sus instituciones, fueron los principales acontecimientos de este cargado año.

Si bien la revelación de una red de corrupción en el sistema judicial, que incluía la protección de varios políticos implicados en distintos delitos, pudo haber mellado la confianza de los peruanos en las instituciones democráticas, los resultados de las investigaciones que estos escándalos desencadenaron no solo sorprendieron a la población, también generaron mayor confianza en los poderes Ejecutivo y Judicial. A diferencia de la mayoría de los países de la región envueltos en el caso Lava Jato, las investigaciones fiscales en Perú progresaron, dictaminándose detención preliminar en la mayoría de los casos.

Sin embargo, las conclusiones del análisis político de este año no son enteramente positivas. Primero, la manera a través de la cual Vizcarra ha lidiado con la reforma política y judicial es, de alguna manera, bastante populista. Vía referéndum e incluyendo la no reelección de congresistas, el presidente ha apelado de manera directa a la población; ello parece ser una buena estrategia 
de respuesta al populismo de Keiko Fujimori y su partido, y al alto nivel de obstrucción que estos presentaron al gobierno de PPK. Las estrategias populistas son antagonistas y dualistas, apelando a la voluntad del ciudadano de a pie (Hawkins y Rovira 2017). Uno de los principales riesgos de estas estrategias es su tendencia a ser fácilmente inclinadas a propuestas autoritarias.

Segundo, si bien el impulso de una reforma constitucional sirvió a Vizcarra como salida ante la polarización Ejecutivo-Legislativo, logrando escapar a la constante obstrucción de la oposición, esta "tregua" no significa un cambio definitivo. Ni el resto de la administración de Vizcarra (hasta 2021), ni mucho menos los próximos gobiernos del Perú están exentos del alto nivel de conflicto que el Congreso ha planteado al Ejecutivo desde el retorno a la democracia. En un contexto de presidentes elegidos bajo un sistema de partidos políticos débiles y un cortoplacismo arraigado a ellos, la presencia de constante polarización entre estos dos poderes del Estado parece inevitable.

Tercero, el fortalecimiento de los poderes Ejecutivo y Judicial vino de la mano del debilitamiento del Poder Legislativo. Un alto nivel de fragmentación ha caracterizado al Congreso: las principales agrupaciones políticas desde la última elección general (Fuerza Popular y Peruanos por el Kambio) han sufrido pérdidas de varios integrantes, y la percepción de la población de este poder del Estado se mantiene extremadamente baja. La baja aprobación del Congreso actúa en detrimento de la mellada percepción de representación democrática que tienen los peruanos, una de las más bajas en la región andina (Aragón 2016; Carrión et al. 2018).

Respuestas a problemas crecientes, como el crimen organizado y la informalidad, requieren de reformas a largo plazo llevadas a cabo por instituciones programáticas. En Perú, los políticos carecen de incentivos para la construcción partidaria y, al mismo tiempo, esta carencia de partidos políticos implica políticas públicas dominadas por una visión de corto plazo, muchas veces alejadas de estándares democráticos (Levitsky 2018). Por ende, a pesar de que las reformas políticas y judiciales impulsadas por Vizcarra puedan ser prometedoras, la continuación de su impulso e implementación en el largo plazo podrían verse obstaculizadas.

\section{REFERENCIAS}

Arce, Moisés y José Incio. 2018. “Peru 2017: An Extreme Case of Divided Government." Revista de Ciencia Política 38 (2): 361-377.

Arévalo, Rosa y Paolo Sosa. 2016. “¿Autoritarismo subnacional en países unitarios? Una reflexión sobre dos casos peruanos (2006-2014)." Revista de Ciencia Política y Gobierno 3 (6): 115-143.

Amaya, Laura. 2018. "El liderazgo de opinión. Conociendo al influencer político peruano." Recuperado el 12 de julio de 2019 de http:/ / revistaargumentos.iep.org.pe/articulos / liderazgo-opinion-conociendo-al-influencer-politico-peruano 
Aragón, Jorge. 2016. "Representación política en los países andinos: crisis y recuperaciones." Revista de Ciencia Política y Gobierno 3 (5): 107-140.

Aragón, Jorge y José Incio. 2014. "La reelección de autoridades regionales y municipales en el Perú, 2006-2014." Recuperado el 12 de julio de 2019 de https:/ / revistaargumentos.iep. org.pe/articulos/la-reeleccion-de-autoridades-regionales-y-municipales-en-el-peru-2006-2014

Aragón, Jorge y Marylia Cruz. 2018. "El estreno de la no reelección inmediata en las elecciones regionales y municipales del 2018." Recuperado el 12 de julio de 2019 de http:/ / revistaargumentos.iep.org.pe/articulos/estreno-la-no-reeleccion-inmediata-las-elecciones-regionales-municipales-del-2018

Banco Central de Reserva del Perú (вСRP). 2019. Notas de Estudios del BCRP. Lima: Banco Central de Reserva del Perú.

Barrenechea, Rodrigo. 2014. Becas, bases y votos. Alianza para el Progreso y la política subnacional en el Perú. Lima: Instituto de Estudios Peruanos.

ввс. 2018а, 21 de marzo. "Perú: renuncia el presidente Pedro Pablo Kuczynski (рРк) entre acusaciones de corrupción y sobornos." Recuperado el 17 de abril de 2019 de https:/ / bbc.in/2WUQj8n

ввс. 2018b, 7 de diciembre. "Referéndum en Perú: por qué el presidente Martín Vizcarra rechaza una reforma que él mismo propuso." Recuperado el 20 de abril de 2019 de https://bbc.in/2WcOxCt

Briceño, Ana. 2018, 4 de agosto. "La Victoria: mafia de alcalde está vinculada con al menos cuatro asesinatos." Recuperado el 20 de abril de 2019 de https: / bit.ly/2As0Pev

Campos, Milagros. 2017. "Transfuguismo y reelección: ¿una forma de sobrevivir en la política?." En Perú: elecciones 2016. Un país dividido y un resultado inesperado, editado por Fernando Tuesta. Lima: Fondo Editorial de la Pontificia Universidad Católica del Perú, 361-382.

Campos, Milagros. 2018. "Los grupos parlamentarios como instituciones de intermediación entre partidos políticos y Congreso." Elecciones 16 (17): 139-168.

Carrión, Julio, Patricia Zárate, María Boidi y Elizabeth Zechmesiter. 2018. Cultura política de la democracia en Perú y en las Américas, 2016-2017: un estudio comparado sobre democracia y gobernabilidad. Lima: Instituto de Estudios Peruanos. En https:/ / www. vanderbilt.edu/lapop/peru/AB2016-17_Peru_Country_Report_Final_W_031918.pdf

Comité Estadístico Interinstitucional de la Criminalidad (CEIC). 2018. Homicidios en el Perú, contándolos uno a uno, 2011-2017. Lima: Instituto Nacional de Estadística e Informática. En https://www.inei.gob.pe/media/MenuRecursivo/publicaciones_digitales/Est/ Lib1532/index.html

Córdova, Beatriz y José Incio. 2013. “La ventaja del incumbente en el ámbito subnacional: un análisis de las dos últimas elecciones municipales en Perú." Papel político 18 (2): 415436.

Dargent, Eduardo y Paula Muñoz. 2016. "Peru: A Close Win For Continuity." Journal of Democracy 27 (4): 145-158.

El Comercio. 2018a, 23 de marzo. “Congreso aceptó la renuncia de PPK a la presidencia del Perú." Recuperado el 22 de abril de 2019 de https: / /bit.ly /2G82Sof

El Comercio. 2018b, 23 de marzo. "Congreso: aceptarán la renuncia, pero rechazan la carta." Recuperado el 22 de abril de 2019 de https:/ / bit.ly/2IMvlSD

El Comercio. 2018c, 19 de octubre. "Villanueva ata confianza a aprobación de reforma hasta el 4 de octubre." Recuperado el 22 de abril de 2019 de https: / / bit.ly/30AIOG3

El Comercio. 2019. Especial "Los peruanos del Lava Jato." Recuperado el 21 de abril de 2019 de https: / / bit.ly/2T9EeOA

Fiscalía de la Nación. 2017. "Fiscal de la Nación crea grupo especial dedicado a investigación del Caso Odebrecht." Recuperado el 24 de abril de 2019 de https:/ /www.mpfn.gob. pe/equipo_especial/?K=1130\&id=7072

Fowks, Jacqueline. 2018a, 10 de enero. "Kuczynski remienda su gabinete para sobrellevar la crisis política." Recuperado el 30 de abril de 2019 de https:/ / bit.ly / 2qLR08u 
Fowks, Jacqueline. 2018b, 29 de enero. "El rechazo al indulto a Fujimori aumenta entre los peruanos." Recuperado el 15 de abril de 2019 de https:/ / bit.ly/2HsPLkC

Fowks, Jacqueline. 2019, 17 de abril. "El 'caso Odebrecht' acorrala a cuatro expresidentes peruanos." Recuperado el 30 de abril de 2019 de https:/ / bit.ly /2VJQId8

Fuentes, Alejandra. 2019. "Ellas también se llaman Perú: sobre los feminicidios recientes." Recuperado el 12 de julio de 2019 de http:/ / www.noticiasser.pe/opinion/ellas-tambien-se-llaman-peru-sobre-los-feminicidios-recientes

Global Corruption Barometer (GCB). 2017. People and Corruption: Latin America and the Caribbean. Transparency International.

González-Ocampos, Ezequiel y Viviana Baraybar. 2019. “Lava Jato beyond Borders. The Uneven Performance of Anticorruption Judicial Efforts in Latin America." Taiwan Journal of Democracy 15 (1): 63-89.

Gorriti, Gustavo. 2017. "De Mani Pulite a Lava Jato." Recuperado el 12 de julio de 2019 de https://idl-reporteros.pe/de-mani-pulite-a-lava-jato-2/

Grompone, Romeo. 2019. "Improvisaciones sobre un mismo repertorio." Recuperado el 12 de julio de 2019 de https:/ /iep.org.pe/noticias/giros-sobre-si-mismo-y-postergaciones-indefinidas/

Hawkins, Kirk A. \& Cristóbal Rovira. 2017. "The Ideational Approach To Populism." Latin American Research Review 52 (4): 513-528.

IDL-Reporteros. S.f. "El caso Lava Juez." Recuperado el 12 de julio de 2019 de https://bit. ly/2JQInRV

IDL-Reporteros. 2018a. "Favores entre colegas." Recuperado el 12 de julio de 2019 de https:/ / bit.ly/2zREkl1

IDL-Reporteros. 2018b. "Botica abierta." Recuperado el 12 de julio de 2019 de https://bit. ly/2OPoUF3

Instituto Nacional de Estadística e Informática (INEI). 2019. Informe técnico: comportamiento de los indicadores de mercado laboral a nivel nacional. Lima: Instituto Nacional de Estadística e Informática.

La Rosa, Rocío. 2018, 22 de abril. “La corrupción, el principal problema del Perú.” Recuperado el 15 de abril de 2019 de https:/ / bit.ly /2K7CygK

La República. 2018a, 21 de junio. “Juan Sheput: 'Que Vizcarra acepte que es un gobierno fujimorista'." Recuperado el 15 de abril de 2019 de https:/ / bit.ly/2K5YrfX.

La República. 2018b, 31 de octubre. "Hacer público el informe Lava Jato desata controversia en el fujimorismo." Recuperado el 15 de abril de 2019 de https:/ / bit.ly / 2Sx9HGB

La República. 2019, 30 de enero. "El fujimorismo pierde poder con las nuevas comisiones." Recuperado el 30 de abril de 2019 de https:/ / larepublica.pe/politica/1404240-fujimorismo-pierde-nuevas-comisiones

Levitsky, Steven. 2018. "Peru: The Institutionalization of Politics without Parties." En Party Systems in Latin America. Institutionalization, Decay, and Collapse, editado por Scott Mainwaring. Cambridge: Cambridge University Press, 326-356.

McNulty, Stephanie. 2017. "Peru 2016: Continuity and Change in an Electoral Year." Revista de Ciencia Política 37 (1): 563-587.

Ministerio de la Mujer y Poblaciones Vulnerables (MIMP). 2019. Reporte estadístico de casos con características de feminicidio registrados por los Centros Emergencia Mujer. Recuperado el 24 de abril de 2019 de https:/ / www.mimp.gob.pe/contigo/contenidos/ pncontigo-articulos.php?codigo $=39$

Muñoz, Paula. 2016. "Clientelismo de campaña, obrismo y corrupción: baja accountability democrática en Perú." En Participación, competencia y representación política. Contribuciones para el debate, editado por Jorge Aragón. Lima: Instituto de Estudios Peruanos, 59-178.

Muñoz, Paula y Yamilé Guibert. 2016. "Perú: el fin del optimismo." Revista de Ciencia Política 36 (1): 313-338.

Office of National Drug Control Policy. 2018. “ONDCP Releases Data on Coca Cultivation and Cocaine Production in Peru and Bolivia." Recuperado el 19 de abril de 2019 de https://bit.ly/2YBb5dA 
Organización Internacional para las Migraciones (огм) y Fondo de las Naciones Unidas para la Infancia (Unicef). 2018. "Monitoreo de flujo de población venezolana en el Perú-DTM." Recuperado el 20 de abril de 2019 de https:/ / bit.ly/2Wm3WwE

Perú21. 2018a, 3 de abril. "Mercedes Aráoz: 'Gobierno de PPK tiene una continuidad a través de Vizcarra'." Recuperado el 15 de abril de 2019 de https:/ / bit.ly/2GyUIWm

Perú21. 2018b, 27 de julio. "Se registran enfrentamientos y disturbios en marcha por la crisis del sistema judicial." Recuperado el 3 de julio de 2019 de https: / / peru21.pe/politica/ desarrolla-marcha-marcha-crisis-sistema-judicial-video-fotos-417351

Perú21. 2019, 10 de enero. "Cinco bancadas se pronuncian tras retiro de moción de censura contra Salaverry." Recuperado el 15 de abril de 2019 de https: / / bit.ly / 2WSdtwf

Rosales, Juan. 2018, 20 de junio. "Congreso aprobó delegar facultades al gobierno de Martín Vizcarra por 60 días." Recuperado el 19 de abril de 2019 de https: / /bit.ly / 2JvBohV

RPP Noticias. 2018, 31 de diciembre. "Pedro Chávarry remueve a fiscales Rafael Vela y José Domingo Pérez del caso Lava Jato." Recuperado el 19 de abril de 2019 de https:/ / bit. ly/2GNfvKr

Santos, Gimena. 2018. "Violencia contra la mujer: cuando la ley no basta ni se implementa." Recuperado el 15 de abril de 2019 de http:/ / www.noticiasser.pe/opinion/violenciacontra-la-mujer-cuando-la-ley-no-basta-ni-se-implementa

Soberón, Ricardo. 2018, 12 de diciembre. "La situación del narcotráfico: Perú 2018." Recuperado el 15 de abril de 2019 de http:/ / www.noticiasser.pe/informe/la-situacion-del-narcotrafico-peru-2018

Sosa, Paolo. 2016. “¿El despertar de la Fuerza Popular? Keiko Fujimori y el partido de las paradojas." En Anticandidatos. El thriller político de las elecciones 2016, editado por Carlos Meléndez. Lima: Planeta, 15-42.

Tola, Raúl. 2017, 24 de febrero. "Keiko Fujimori, investigada en Perú por lavado de activos." Recuperado el 29 de abril de 2019 de https:/ / bit.ly/30xOuR8

Tola, Raúl. 2018, 3 de noviembre. "Keiko Fujimori: historia de una caída." Recuperado el 19 de abril de 2019 de https: / / bit.ly / 2HrzCvK

Trome. 2018, 28 de julio. “¡Cárcel para los corruptos!." Recuperado el 19 de abril de 2019 de https://bit.ly/2M412z0

Urrutia, Adriana. 2011. "Que la Fuerza (2011) esté con Keiko: el nuevo baile del fujimorismo. El fujimorismo, su organización y sus estrategias de campaña." En Poscandidatos: guía analítica de supervivencia hasta las próximas elecciones, editado por Carlos Meléndez. Lima: Mitin y 50+1, 91-120.

Valladares, Jorge. 2010. "Representación, competencia y unidad en el Congreso peruano." En La iniciación de la política. El Perú político en perspectiva comparada, editado por Alberto Vergara y Carlos Meléndez. Lima: Fondo Editorial de la Pontificia Universidad Católica del Perú, 183-210.

Vega, Eduardo, José Rojas, Lorena Elías, José Koechlin y Ximena Solórzano. 2018. El círculo de la corrupción en los gobiernos regionales. Los casos de Cusco, Ayacucho, Moquegua, Piura y Madre de Dios. Lima: Konrad-Adenauer-Stiftung y Universidad Ruiz de Montoya.

Vera, Enrique y Junior Meza. 2018, 4 de noviembre. “Un pueblo del vRAEm queda deshabitado tras asesinatos selectivos." Recuperado el 15 de abril de 2019 de https:/ / bit.ly/2Hre$\mathrm{c} 2 \mathrm{~b}$

Zavaleta, Mauricio. 2014. Coaliciones de independientes. Las reglas no escritas de la política electoral. Lima: Instituto de Estudios Peruanos.

Recibido: 20 de mayo de 2019

Aceptado: 15 de julio de 2019 
Zoila Ponce de León es profesora del Departamento de Política de la Universidad de Washington and Lee. Es Ph.D. en Ciencia Política por la Universidad de Carolina del Norte en Chapel Hill. Sus temas de interés son la economía política comparada, las políticas sociales, y la opinión pública. Email: zponcedeleon@wlu.edu

Luis García Ayala es licenciado en Ciencia Política y Gobierno por la Pontificia Universidad Católica del Perú. Actualmente es estudiante del programa de doctorado de Ciencia Política por la Universidad de Temple, en Filadelfia, Estados Unidos. Email: tul03112@temple.edu 